\title{
Analysis of Silicones Released from Household Items and Baby Articles by Direct Analysis in Real Time-Mass Spectrometry
}

\author{
Jürgen H. Gross
}

Institute of Organic Chemistry, Heidelberg University, Im Neuenheimer Feld 270, 69120, Heidelberg, Germany

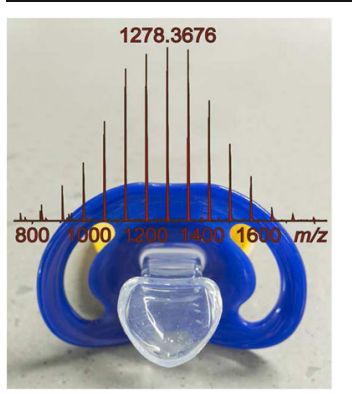

\begin{abstract}
Direct analysis in real time-mass spectrometry (DART-MS) enables screening of articles of daily use made of polydimethylsiloxanes (PDMS), commonly known as silicone rubber, to assess their tendency to release low molecular weight silicone oligomers. DART-MS analyses were performed on a Fourier transform ion cyclotron resonance (FT-ICR) mass spectrometer. Flexible silicone baking molds, a watch band, and a dough scraper, as baby articles different brands of pacifiers, nipples, and a teething ring have been examined. While somewhat arbitrarily chosen, the set can be regarded as representative of household items, baby articles, and other objects made of silicone rubber. For comparison, two brands of silicone septa and as blanks a glass slide and a latex pacifier were included. Differences between
\end{abstract} the objects were mainly observed in terms of molecular weight distribution and occasional release of other compounds in addition to PDMS. Other than that, all objects made of silicone rubber released significant amounts of PDMS during DART analysis. To provide a coarse quantification, a calibration based on silicone oil was established, which delivered PDMS losses from $20 \mu \mathrm{g}$ to $>100 \mu \mathrm{g}$ during the 16 -s period per measurement. Also, the extraction of baking molds in rapeseed oil demonstrated a PDMS release at the level of $1 \mathrm{\mu g} \mathrm{mg}^{-1}$. These findings indicate a potential health hazard from frequent or long-term use of such items. This work does not intend to blame certain brands of such articles. Nonetheless, a higher level of awareness of this source of daily silicone intake is suggested.

Keywords: Direct analysis in real time (DART), Release of silicones, Polydimethylsiloxanes (PDMS), Silicone rubber, Quantification, Household items, Baby articles, Health risk, Fourier transform ion cyclotron resonance

Received: 10 August 2014/Revised: 14 October 2014/Accepted: 14 October 2014/Published Online: 16 December 2014

\section{Introduction}

$\mathrm{P}$ olydimethylsiloxane (PDMS) and various types of related silicone polymers represent an important class of widely employed synthetic polymers. Major applications of silicones include weather sealing, fabric coatings and water repellents, wires and cables, tubing and septa, hydraulics, automotive, lubrication, electronics, and agricultural adjuvant chemicals. A second group of uses, which may be less obvious for the "average consumer," comprises sun care and other cosmetic products, watch bands, car washing formulations, and household cleaners. Silicones may come in contact with food as is the

Electronic supplementary material The online version of this article (doi:10.1007/s13361-014-1042-5) contains supplementary material, which is available to authorized users.

Correspondence to: Jürgen Gross; e-mail: juergen.gross@oci.uni-heidelberg.de case with kitchenware like baking molds, dough scrapers, beakers, or food packaging. Finally, there are numerous silicone baby articles like pacifiers, nipples, teething rings, and soft toys, which are extensively used and chewed by small children.

The release of plasticizers from highly flexible household utensils, toys, and food containers is not uncommon; low attention appears to be paid to the easy and substantial release of low molecular weight silicone oligomers. However, when studied, the long-term exposure of humans to silicones was found to induce adverse health effects. For example, adverse health effects of silicones released under physiological conditions from breast implants are discussed in the context of breast cancer [1], fibrosis [2], autoimmunity [3], and inflammatory processes [4]. Nonetheless, the use of PDMS and related silicones stills seems to increase and silicone has even been suggested as a potent absorbing material for 3-alkyl-methoxypyrazine responsible for undesirable aromas in wine [5]. 
Direct analysis in real time-mass spectrometry (DART-MS) $[6,7]$ is a proven method for quick and facile analysis of a large variety of samples. DART-MS belongs to the growing group of ambient mass spectrometry [8-10]. Characteristic for ambient MS is the direct exposure of the sample to an ionizing gas at the open atmosphere. In DART-MS, the sample surface is exposed to a heated helium gas stream containing electronically excited atoms (metastable helium atoms). The hot helium gas thus affects both evaporation and ionization of analyte molecules.

This way, DART-MS may be used to examine entire objects in the open environment while maintaining sample integrity [11]. To do so, an object is simply positioned in front of an atmospheric pressure interface and molecules released from the sample become ionized and transferred into the mass analyzer.

DART-MS is compatible with positive-ion and negative-ion modes of operation [6], though the majority of DART-MS applications still uses positive-ion mode. The features of DART-MS and ion formation processes in positive-ion DART are described in References [6, 7, 11-15]. DART-MS has numerous applications in chemical analysis [16], forensics [10], drug testing [17], food quality and safety analysis [11, 18], and many other fields $[8,10,11,16,17,19,20]$.

Quantification, generally at reasonable levels of precision and accuracy, has also been done by DART-MS. For example, pharmaceutical drugs were quantified in biological fluids [21] and samples from in vivo pharmacokinetic studies were analyzed [22]. Very good linear calibration curves could be obtained in the analysis of warfare agents where linear DART response was achieved over about three orders of magnitude [23]. Another example of DART quantification is presented by the analysis of six carbon sugars in switchgrass, where calibration curves with wide linear ranges, correlation coefficients better than 0.997 , and recoveries of $94.9 \%$ to $103.0 \%$ were realized [24]. A coarse quantification of organic UV filters of four parabens in several different types of cosmetic products was also performed by DART-MS [25]. DART was employed to analyze contaminations of soil with aspirin, diphenylamine, and pentachlorophenol in a semiquantitative manner [26]. Generally, some sort of matrix effects were observed in that differences in DART response did occur between neat analyte and analyte contained in some sample matrix (e.g., limitations of DART-MS became obvious during the quantification of 5hydroxymethylfurfural in honey as an accurate analyte quantitation was impossible because thermal degradation of the carbohydrate matrix interfered with the analyte [27]).

DART-MS has been employed for the direct determination of stabilizers in polymeric materials [28] and for the detection of primary aromatic amine antioxidants released from kitchen utensils [29]. The latter two applications demonstrate the ability of DART to detect components, even of low volatility, embedded in the solid matrix of a polymer. Among other organic contaminants, PDMS has been analyzed by DART-MS in agricultural biosolids [30]. The efficient detection of PDMS by positive-ion DART up to $\mathrm{m} / \mathrm{z} 3000$ has also been employed for reliable and facile mass calibration covering the $\mathrm{m} / \mathrm{z} 200$ 3000 range [31]. These findings indicate that DART is suitable for detecting the release of low to medium molecular weight PDMS oligomers if PDMS is prone to release such compounds.

Here, the release of silicone oligomers from articles of daily use has been examined by their exposure to a DART ion source attached to a Fourier transform ion cyclotron resonance (FTICR) mass spectrometer. As representative articles of daily use, household utensils like flexible silicone baking molds, a dough scraper, and a watch band, as baby articles some pacifiers, nipples, and a teething ring have been chosen (Table 1 and Figure S1 in the Supplementary Material). They were analyzed by positive-ion DART-FT-ICR-MS and their spectra were compared with those of more technical silicone products like silicone septa and silicone oil. The amount of silicones released from most of these articles of daily use turned out to be in the same order of magnitude as detected by the direct supply of silicone oil or grease to the DART source in transmission mode [31].

Thus, a substantial dose of silicones may be taken up from such articles by humans, in particular during elongated exposure under extracting conditions as in the case of pacifiers or teething rings or when items are used at elevated temperature as is the case with baking molds. The immediate strong release of silicones at the elevated temperature of DART analysis indicates a potential health risk from daily use of such silicone items.

The intention of this work is not to blame these particular products or their manufacturers - they are just representative of this abundant type of products - but to raise an alertness for the health implications and to initiate thinking about alternatives.

\section{Experimental}

\section{General Instrumentation}

The analyses were performed by use of a Bruker Apex-Qe Fourier transform ion cyclotron resonance mass spectrometer (Bruker Daltonik GmbH, Bremen, Germany) equipped with a 9.4 T superconducting magnet and an ESI-to-MALDI switchable Dual Source MTP. The analyzer of this instrument, actually a quadrupole-ICR hybrid, comprises a rf-only hexapole (h1), a selection rf/DC quadrupole (Q), a second rf-only hexapole ( $\mathrm{h} 2$ ), and a high voltage ion transfer flight tube to bring ions from $\mathrm{h} 2$ into the ICR cell. Ions were accumulated for $1.0 \mathrm{~s}$ prior to ICR mass analysis in rf-only hexapole h2. Ions were excited and detected using standard settings from previous DART work [31, 32]. The range $m / z 200-2500$ was selected, which resulted in a resolving power of 80.000 at $m / z 684$ with the $1 \mathrm{M}$ transient. The instrument was controlled by the Bruker ApexControl software (V 3.0.0) and data analysis was performed using the Bruker DataAnalysis software (V 4.0).

\section{DART Setup}

The DART-SVP ionization source (IonSense Inc., Saugus, MA, USA) was mounted on the ESI interface of the ion source 
via the so-called Vapur Interface that provides an additional pumping stage in order to avoid a compromised instrument vacuum due to the helium flow directly into the orifice of the API interface.

For external mass calibration, transmission mode DART was employed by mounting the Open Source. The Open Source assembly consists of a card holder frame located beneath a compact hood, and makes use of disposable cardboard sample holders. The sample is desorbed after deposition on a fine metal wire mesh [33-35]. External mass calibration in positive-ion DART mode was established on either silicone oil (VWR Silikonöl 47 V 350; VWR International GmbH, Bruchsal, Germany) [31] or 1-butyl-3-methylimidazolium tricyanomethide (Merck KGaA, Darmstadt, Germany), an ionic liquid (IL) [36], both employed as solutions at $1 \mathrm{mg} \mathrm{mL}^{-1}$. For DART-MS, $3 \mu \mathrm{L}$ of the respective solution was applied to the mesh of the Open Source cards. Temperature of the DART source was set to $300^{\circ} \mathrm{C}$ for silicone oil, $450^{\circ} \mathrm{C}$ for the IL.

\section{Analysis of Objects}

For the analysis of the household items, the DART-SVP ionization source was mounted at an angle of $45^{\circ}$ relative to the axis of the ceramics tube of the Vapur Interface. The angle mount was recessed to the $20 \mathrm{~mm}$ position on the sliding rail and the ionization source was shifted vertically by $6 \mathrm{~mm}$ using the knurled nut for adjustment of the device. Then, the entire group of objects were manually positioned about halfway between helium exit and capillary entrance and directly exposed to the ionizing gas. For all silicone rubber items, the gas was uniformly set to $300^{\circ} \mathrm{C}$ and the ions were accumulated for $1.0 \mathrm{~s}$ prior to ICR mass analysis. Per magnitude spectrum, 16 transients were accumulated. Broadband spectra were acquired with $1 \mathrm{M}$ data points. Repeated measurements of the same object showed only moderate variation in intensity and $\mathrm{m} / \mathrm{z}$ distribution of the signals.

\section{Objects Analyzed}

The items were obtained from different sources. Baking molds were from the author's household and have had multiple uses prior to DART analysis. Pacifiers, nipples, and other articles were purchased in a local drugstore (Lorsch, Germany) or in a US supermarket (Baltimore, MD). Silicone septa were taken from stock in the laboratory (Table 1 and Figure S1 in Supplementary Material).

\section{Quantification}

Solutions of silicone oil in dichloromethane at concentrations from 0.01 to $10 \mathrm{mg} \mu \mathrm{L}^{-1}$ were prepared and spots of several microliters were applied to a glass slide. The solvent was allowed to evaporate and the residual silicone oil spot was positioned analogous to the silicone rubber items and subjected to DART analysis. Silicone peaks having relative intensities above $2 \%$ and of signal-to-noise ratio $>3$ were retrieved from the spectrum list, exported to Microsoft Excel software, and
Table 1. Compilation of Silicone Rubber Objects Analyzed by DART-MS

\begin{tabular}{llll}
\hline Category & Product & Brand and type & $\begin{array}{l}\text { Source / } \\
\text { vendor* }\end{array}$ \\
\hline Household & $\begin{array}{l}\text { Dough scraper } \\
\text { Baking mold }\end{array}$ & $\begin{array}{l}\text { Farberware Professional } \\
\text { Kaiser, rectangular }\end{array}$ & US \\
& Baking mold & Pavoni, muffin & HO \\
Daily use & Baking mold & Pavoni, braided ring & HO \\
Baby article & Wrist watch & No-name product & HO \\
& Pacifier & NUK Happy Days & DE \\
& Pacifier & NUK Happy Kids, latex & DE \\
& Pacifier & Playtex ortho PRO & US \\
& Nipple & Babylove Trinksauger & DE \\
& Nipple & Parents Choice & US \\
& Teething ring & NUK & DE \\
Laboratory & Septum & SGE, silicone, yellow & LA \\
& Septum & Neolab, silicone, blue/white & LA \\
\hline
\end{tabular}

*DE: Drugstore, Lorsch, Germany; US: Supermarket, Baltimore, MD; HO: already used author's household; LA: taken from stock in laboratory

their individual intensities (in counts) were summed up to yield a total signal count. The increase of the total signal count was best represented by a logarithmic fit, which was then used as the calibration curve.

\section{Extraction Experiments}

To simulate typical baking conditions, slices were cut off from the baking molds and $1.0 \mathrm{~g}$ of this material was covered with $2 \mathrm{~mL}$ of rapeseed oil in a $25 \mathrm{~mL}$ glass beaker. The beaker was sealed with aluminum foil and baked for $1 \mathrm{~h}$ at $180^{\circ} \mathrm{C}$ in a drying oven. A blank sample of rapeseed oil was also baked at $180^{\circ} \mathrm{C}$ for $1 \mathrm{~h}$. After cooling, $2 \mu \mathrm{L}$ samples of the oil were placed on a glass slide and measured under the same conditions as above.

Aqueous extraction of pacifiers and nipples was performed by storing $1.0 \mathrm{~g}$ of sliced material in $10 \mathrm{~mL}$ of water at $35^{\circ} \mathrm{C}$ overnight. The water was extracted with $0.5 \mathrm{~mL}$ of dichloromethane and the extract was analyzed.

\section{Results and Discussion}

\section{Identification of Silicones}

In positive-ion DART-MS, PDMS products deliver signals over a comparatively wide $\mathrm{m} / \mathrm{z}$ range. Generally, three major polydimethylsiloxane ion series are observed [37]. Characteristically, each of the ion series of polydimethylsiloxanes is spaced at $\Delta m / z=74.018791$, which reflects the mass of the $\mathrm{OSi}\left(\mathrm{CH}_{3}\right)_{2}$ monomeric building blocks. The first ionic series is attributed to cyclic fragments minus one methyl group, i.e., $\left[\left(\mathrm{OSi}\left(\mathrm{CH}_{3}\right)_{2}\right)_{\mathrm{n}}-\right.$ $\left.\mathrm{CH}_{3}\right]^{+}$, presumably formed by loss of $\mathrm{CH}_{4}$ or larger moieties from protonated molecules; ions therefore occur at nominal $m / z=(n \times 74)-15$. The second ion series corresponds to cyclic silicone fragments of the type $\left[\left(\mathrm{OSi}\left(\mathrm{CH}_{3}\right)_{2}\right)_{\mathrm{n}}+\mathrm{H}\right]^{+}$, delivering ions at nominal $\mathrm{m} / \mathrm{z}=(n \times 74)+1$. The third series is obtained by ammonium ion adduct formation rather than protonation in analogy to the above, i.e., incorporates $\left[\left(\mathrm{OSi}\left(\mathrm{CH}_{3}\right)_{2}\right)_{\mathrm{n}}+\mathrm{NH}_{4}\right]^{+}$ ions that yield peaks at $m / z=(n \times 74)+18$, i.e., at nominal vales 
of $m / z 536,610,684,758$, and so on. In positive-ion DART-MS, this third series dominates by far [31]. Here, the signals usually started from $m / z 610$, i.e., at $\left[\mathrm{C}_{16} \mathrm{H}_{52} \mathrm{NO}_{8} \mathrm{Si}_{8}\right]^{+}$, but often only from slightly higher $\mathrm{m} / \mathrm{z}$ values, and extended into the $\mathrm{m} / \mathrm{z} 1800$ 2000 range. This upper limit corresponds to PDMS ions containing about $25 \mathrm{Si}$ atoms, e.g., $\left[\mathrm{C}_{50} \mathrm{H}_{154} \mathrm{NO}_{25} \mathrm{Si}_{25}\right]^{+}, m / z$ 1868.50361 .

The identification of the signals observed as ions from PDMS is explained along the partial DART spectrum of a Pavoni braided ring baking mold in the $m / z$ 500-1000 range (Figure 1a). The ion series observed is in accordance with the $\left[\left(\mathrm{OSi}\left(\mathrm{CH}_{3}\right)_{2}\right)_{\mathrm{n}}+\mathrm{NH}_{4}\right]^{+}$ions described above and it exhibits mass differences within $0.0025 \mathrm{u}$ of the calculated $\Delta m / z=$ 74.01879 for $\mathrm{OSi}\left(\mathrm{CH}_{3}\right)_{2}$ units. This spectrum was obtained based on an external mass calibration. The PDMS ionic formulas calculated for the signals at $\mathrm{m} / \mathrm{z} 536.16442,610.18301$, 684.20162, 758.22019, 832.23886, 906.25741, and 980.27616 are also provided (Figure 1b). Correct formulas are identified by their equal number of $\mathrm{Si}$ and $\mathrm{O}$ atoms and are highlighted in this list. They correspond to ammonium adduct ions; hence, there is one nitrogen contained. The ionic formulas are found within 2 ppm mass error. Furthermore, the isotopic patterns of all signals reveal the presence of numerous $\mathrm{Si}$ atoms. As a proof, the isotopic pattern of the signal at $\mathrm{m} / \mathrm{z} 832.23886$ is

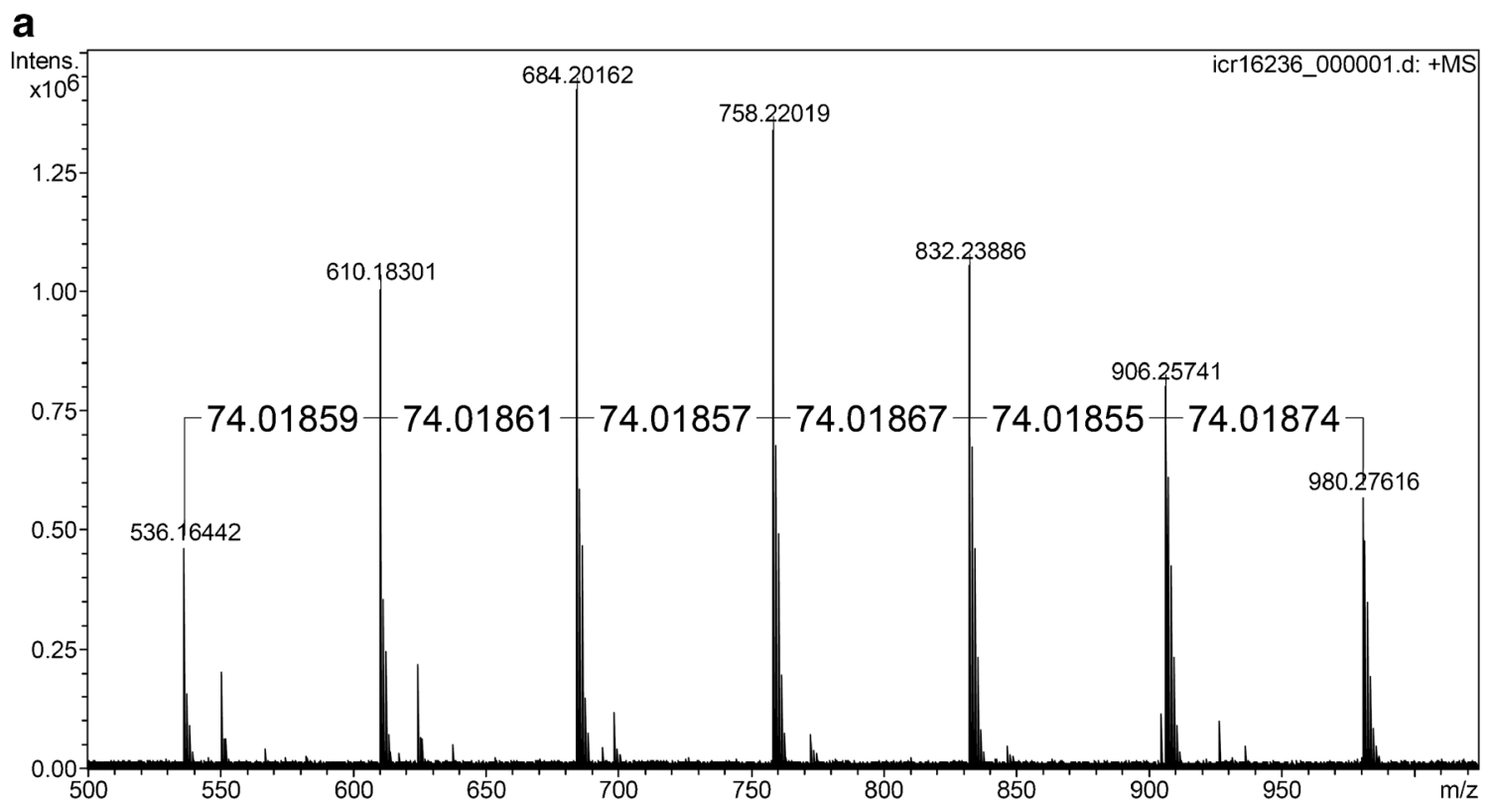

b

\begin{tabular}{|c|c|}
\hline Meas. $\mathrm{m} / \mathrm{z}$ & Formula \\
\hline 536.16442 & $\mathrm{C} 14 \mathrm{H} 46 \mathrm{NO} 7 \mathrm{Si} 7$ \\
\hline \multirow[t]{2}{*}{610.18301} & C $17 \mathrm{H} 48 \mathrm{NO} 11 \mathrm{Si} 6$ \\
\hline & C 16 H 52 N O 8 Si 8 \\
\hline 684.20162 & $\begin{array}{l}\text { C } 19 \text { H } 54 \text { NO } 12 \mathrm{Si} 7 \\
\text { C } 18 \text { H } 58 \text { NO } 9 \mathrm{Si} 9\end{array}$ \\
\hline \multirow[t]{5}{*}{758.22019} & $\begin{array}{l}\mathrm{C} 25 \mathrm{H} 56 \mathrm{NO} 12 \mathrm{Si} 7 \\
\mathrm{C} 21 \mathrm{H} 60 \mathrm{~N} \mathrm{O} 13 \mathrm{Si} 8\end{array}$ \\
\hline & C $24 \mathrm{H} 60 \mathrm{NO} 9 \mathrm{Si} 9$ \\
\hline & C $20 \mathrm{H} 64 \mathrm{~N} \mathrm{O} 10 \mathrm{Si} 10$ \\
\hline & C 23 H 64 N O 6 Si 11 \\
\hline & C 19 H 68 N O 7 Si 12 \\
\hline \multirow[t]{6}{*}{832.23886} & $\mathrm{C} 27 \mathrm{H} 62 \mathrm{NO} 13 \mathrm{Si} 8$ \\
\hline & C $23 \mathrm{H} 66 \mathrm{NO} 14 \mathrm{Si} 9$ \\
\hline & $\mathrm{C} 26 \mathrm{H} 66 \mathrm{~N} O 10 \mathrm{Si} 10$ \\
\hline & C $22 \mathrm{H} 70 \mathrm{~N} O 11 \mathrm{Si} 11$ \\
\hline & C 25 H 70 N O 7 Si 12 \\
\hline & C 21 H 74 N O 8 Si 13 \\
\hline \multirow[t]{5}{*}{906.25741} & C 29 H 68 N O 14 Si 9 \\
\hline & $\mathrm{C} 28 \mathrm{H} 72 \mathrm{~N} O 11 \mathrm{Si} 11$ \\
\hline & C $24 \mathrm{H} 76 \mathrm{~N} \mathrm{O} 12 \mathrm{Si} 12$ \\
\hline & C $27 \mathrm{H} 76 \mathrm{NO} 8 \mathrm{Si} 13$ \\
\hline & C 23 H 80 N O 9 Si 14 \\
\hline \multirow[t]{3}{*}{980.27616} & C $30 \mathrm{H} 78 \mathrm{~N}$ O $12 \mathrm{Si} 12$ \\
\hline & $\mathrm{C} 26 \mathrm{H} 82 \mathrm{~N} \mathrm{O} 13 \mathrm{Si} 13$ \\
\hline & C 29 H 82 N O 9 Si 14 \\
\hline
\end{tabular}

$\begin{array}{rr}\mathrm{m} / \mathrm{z} & \text { err }[\mathrm{ppm}] \\ 536.16536 & 1.8 \\ 610.18375 & 1.2 \\ 610.18416 & 1.9 \\ 684.20254 & 1.3 \\ 684.20295 & 1.9 \\ 758.21819 & -2.6 \\ 758.22133 & 1.5 \\ 758.21860 & -2.1 \\ 758.22174 & 2.0 \\ 758.21901 & -1.6 \\ 758.22215 & 2.6 \\ 832.23698 & -2.3 \\ 832.24012 & 1.5 \\ 832.23739 & -1.8 \\ 832.24053 & 2.0 \\ 832.23780 & -1.3 \\ 832.24094 & 2.5 \\ 906.25577 & -1.8 \\ 906.25618 & -1.4 \\ 906.25932 & 2.1 \\ 906.25659 & -0.9 \\ 906.25973 & 2.6 \\ 980.27497 & -1.2 \\ 980.27811 & 2.0 \\ 980.27538 & -0.8\end{array}$

C

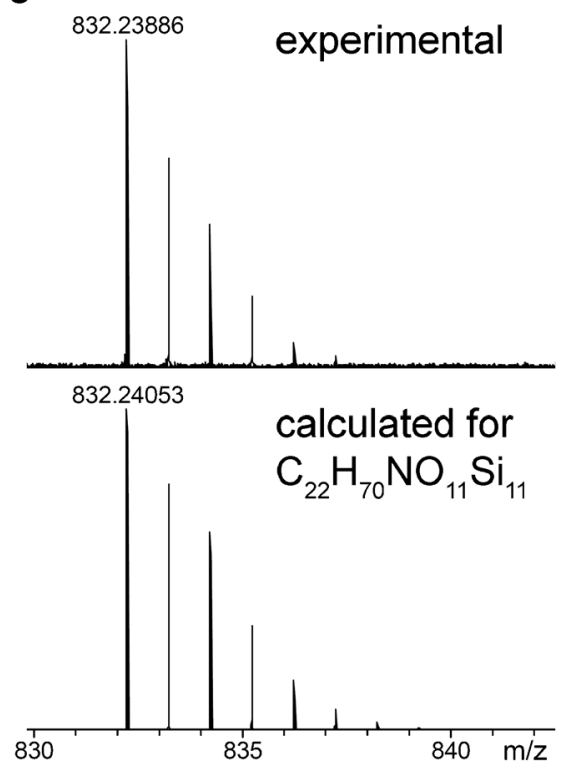

Figure 1. Partial positive-ion DART spectrum of a Pavoni braided ring baking mold at $300^{\circ} \mathrm{C}$ with the mass differences annotated between adjacent peaks (a); the values are close to the theoretical $\Delta m / z=74.018791$ of OSi $\left(\mathrm{CH}_{3}\right)_{2}$. The correct PDMS ionic formulas are marked in the list (b). The isotopic pattern of the signal at $\mathrm{m} / \mathrm{z} 832.23886$ is compared to the theoretical pattern (c) 
compared with the theoretical pattern as calculated for the assigned ionic formula $\left[\mathrm{C}_{22} \mathrm{H}_{70} \mathrm{Si}_{11} \mathrm{O}_{11} \mathrm{~N}\right]^{+}$(Figure 1c).

Silicone septa are frequently used in different laboratory applications. They should neither easily be extracted by solvents nor should they release such material upon thermal stress. In the context of the present study, two types of silicone septa were included to serve as a reference of silicone objects. They should provide DART spectra of authentic silicone rubber compared with silicone oil and grease, and allow recognizing characteristic features of those spectra in case of doubt about the origin of signals. The identification of silicones is also supported by equal appearance of spectra obtained from silicone septa or silicone oil. Thus, the origin of the spectra is clearly related to the release of PDMS from the objects under study (i.e., from the baking mold discussed in the above paragraph). All other DART spectra obtained in this study exhibit close similarity (Figures S5-S17 of the Supplementary Material).

\section{Standardizing the DART Gas Temperature}

For reliable comparison of all articles, a standard temperature for the helium gas had to be defined. This value was chosen after scanning the DART gas temperature. Here, the influence of the temperature is demonstrated along the DART spectra of a Kaiser rectangular baking mold as obtained upon exposure to DART gas at 150 to $350^{\circ} \mathrm{C}$ (Figure 2). The variation of the DART spectra with rising temperature is quite obvious. At $150^{\circ} \mathrm{C}$, only low-mass silicones are observed and the intensity of the most abundant signal corresponds to $1.1 \times 10^{6}$ counts. As the temperature is increased in increments of $50^{\circ} \mathrm{C}$, the distribution expands to higher mass, shows more signals, and the intensity of the signals rises up to $3.8 \times 10^{6}$ counts. At $350^{\circ} \mathrm{C}$, the series of silicone ions expands from $\mathrm{m} / \mathrm{z} 610$ to beyond $\mathrm{m} / \mathrm{z}$ 1400. Based on these observations, a standard temperature of $300^{\circ} \mathrm{C}$ was defined and applied to analyze all silicone rubber articles.

As a consequence, the role of eventually occurring thermal decomposition needs to be considered. Baking molds are supposed to withstand heat for an elongated period, typically 45 $60 \mathrm{~min}$. This is confirmed by the imprinted temperature limits for use, which are explicitly specified to be $260^{\circ} \mathrm{C}$ in case of the Farberware dough scraper and even $280^{\circ} \mathrm{C}$ for the Pavoni braided ring baking mold (Figure S3 of the Supplementary Material). The manufacturer's statement is obviously intended to provide confidence for the potential user that this product is safe for use in direct contact with food even when exposed to high temperature for about $1 \mathrm{~h}$. Admittedly, exposure of a pacifier to the DART gas at $300^{\circ} \mathrm{C}$ does not exactly reflect the conditions of normal use; it may, however, simulate the effect of hours of use under physiological conditions. Baby articles under study are all intended for long-time use in babies' mouths either to supply milk or other drinks or to calm down as is the case with pacifiers and teething rings. They are thus operated under aqueous extracting conditions and, therefore, potentially prone to release low molecular weight oligomers directly into the child's intestinal tract. Wrist watch bands and other wrist bands are frequently made of silicone rubber. They are exposed to moist skin and sweat, in particular because of increased transpiration in the contact zone with the polymer. One no-name wrist watch band has been included here for comparison.

None of the items did show visible marks, discoloration, or the like after analysis (for a demonstration with the Playtex ortho PRO pacifier cf. Figures S3 and S4 of the Supplementary Material). Overall, the conditions chosen for analysis seem not to affect the surface integrity of the objects. Thus, the release of medium molecular weight silicones is not the consequence of major decomposition due to overly harsh conditions. Rather, it represents an intrinsic property of those silicone rubbers to release medium molecular weight silicones as "natural" components of these materials analogous to what has been observed in case of stabilizers and plasticizers in other polymeric materials $[28,29]$.

\section{Release of Additional Compounds}

Most of the object analyzed released almost only PDMS. The spectra of some sample showed additional ionic series, typically in the low-mass range of the spectra. For example, the DART spectrum of the NUK Happy Days pacifier reveals the release of some low-mass polyethylene glycols that are detected as $\left[\mathrm{PEG}+\mathrm{NH}_{4}\right]^{+}$ions (Figure 3). This spectrum has been recalibrated internally on silicone signals in the range of $\mathrm{m} / \mathrm{z}$ 684 to 1202 prior to formula assignment to the additional compounds.

As a second object, delivering ion series in addition to silicones is presented by the Kaiser rectangular baking mold (Figure 2). Its DART spectra show tightly spaced signals in the $m / z$ 300-600 range. Based on previous actual uses of this mold, they were first assumed to correspond to residual components of fats (e.g., diacylglycerols). However, after internal calibration on the silicones, formulas of the type $\left[\mathrm{C}_{\mathrm{n}} \mathrm{H}_{2 \mathrm{n}} \mathrm{N}_{5}\right]^{+}$, $\left[\mathrm{C}_{\mathrm{n}} \mathrm{H}_{2 \mathrm{n}} \mathrm{N}_{5} \mathrm{O}\right]^{+}$, and $\left[\mathrm{C}_{\mathrm{n}} \mathrm{H}_{2 \mathrm{n}} \mathrm{N}_{5} \mathrm{O}_{2}\right]^{+}$were retrieved. This series also did not appear in the spectra of the otherwise very similar Pavoni baking molds. The identification of these additional compounds has not been pursued further. Other occasionally occurring additives occurring in the DART spectra were plasticizers, for example.

\section{Quantification of Silicone Release}

It is not straightforward to determine the amount of PDMS released from a silicone rubber surface upon exposure to the DART gas at $300^{\circ} \mathrm{C}$. Nonetheless, a realistic estimate can be obtained by comparison of the signal intensity generated by DART ionization of known amounts of silicone oil under comparable conditions. Therefore, solutions of silicone oil in dichloromethane were prepared at concentrations ranging from 0.01 to $10 \mathrm{mg} \mu \mathrm{L}^{-1}$ and spots of several microliters were applied to a glass slide. After evaporation of the solvent, the residual silicone oil spot was positioned analogous to the silicone rubber items and subjected to DART analysis. Glass 


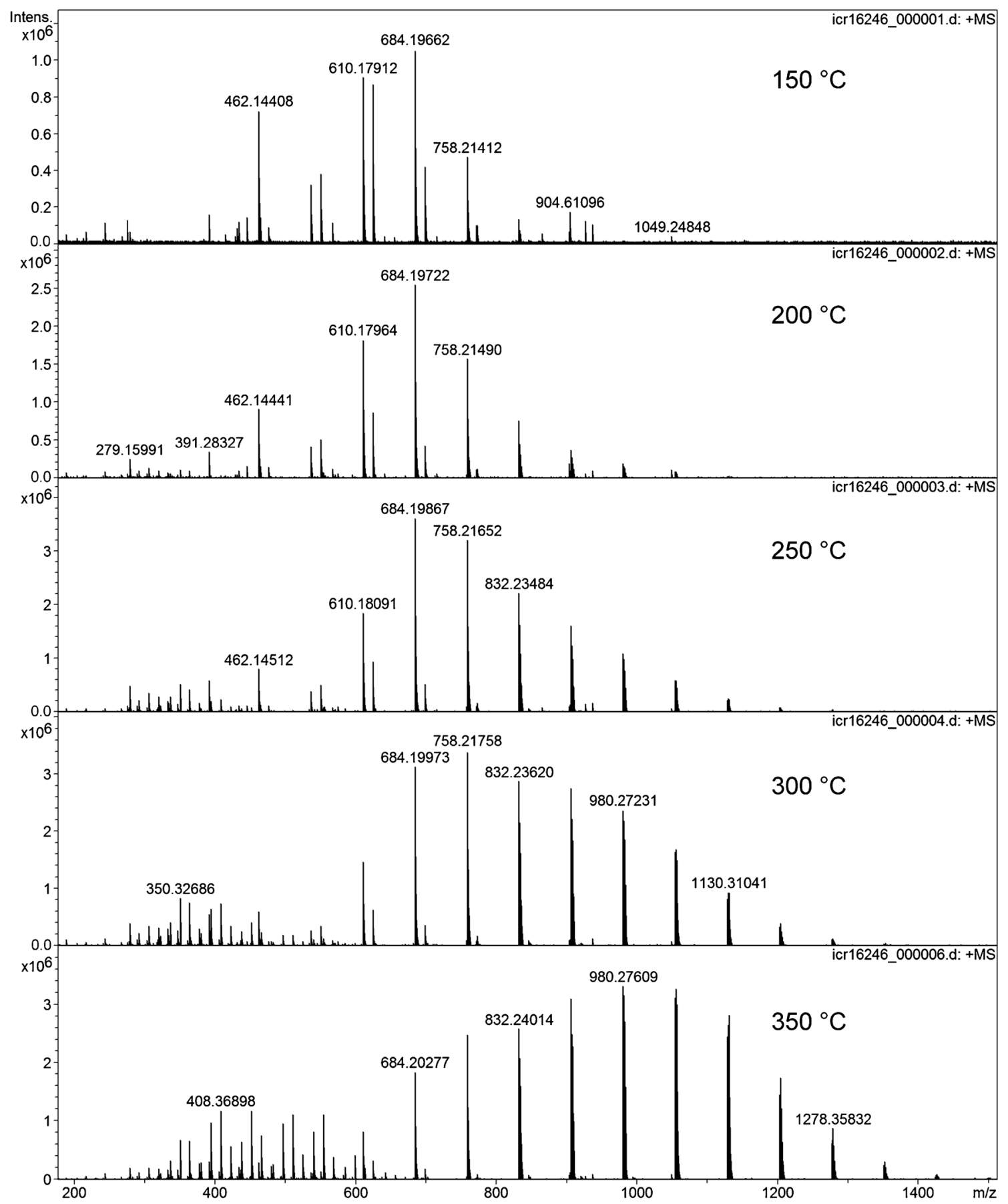

Figure 2. Positive-ion DART spectra of a Kaiser rectangular baking mold as obtained upon exposure to DART gas at 150 to $350^{\circ} \mathrm{C}$. For comparison of all articles, a standard of $300^{\circ} \mathrm{C}$ was set

slides were employed as sample support because (1) glass has low thermal conductivity and should heat up similar to silicone, (2) it is chemically inert, and (3) it offers a plane surface similar to the spatial arrangement achieved with the objects under study.

To determine the spectral background, the DART spectrum of a clean glass slide was measured as a blank (Figure S18 of the Supplementary Material). The low-intensity signals at $\mathrm{m} / \mathrm{z}$ $536,610,684$, and 758 in this spectrum are due to silicone background; the ions causing them are also present in the silicone oil and other silicones. These four background peaks were observed ever since the installation of the source and are not due to residual sample from excessive analysis of silicone oil and rubber samples. In fact, their occurrence induced previous work to establish a mass calibration based on silicone oil.

It turned out that in the order of $1 \mu \mathrm{g}$ of PDMS was required on the glass slide to obtain signals of reasonable signal-to-noise ratio $(\mathrm{s} / \mathrm{n})$. Positive-ion DART mass spectra of selected runs of 


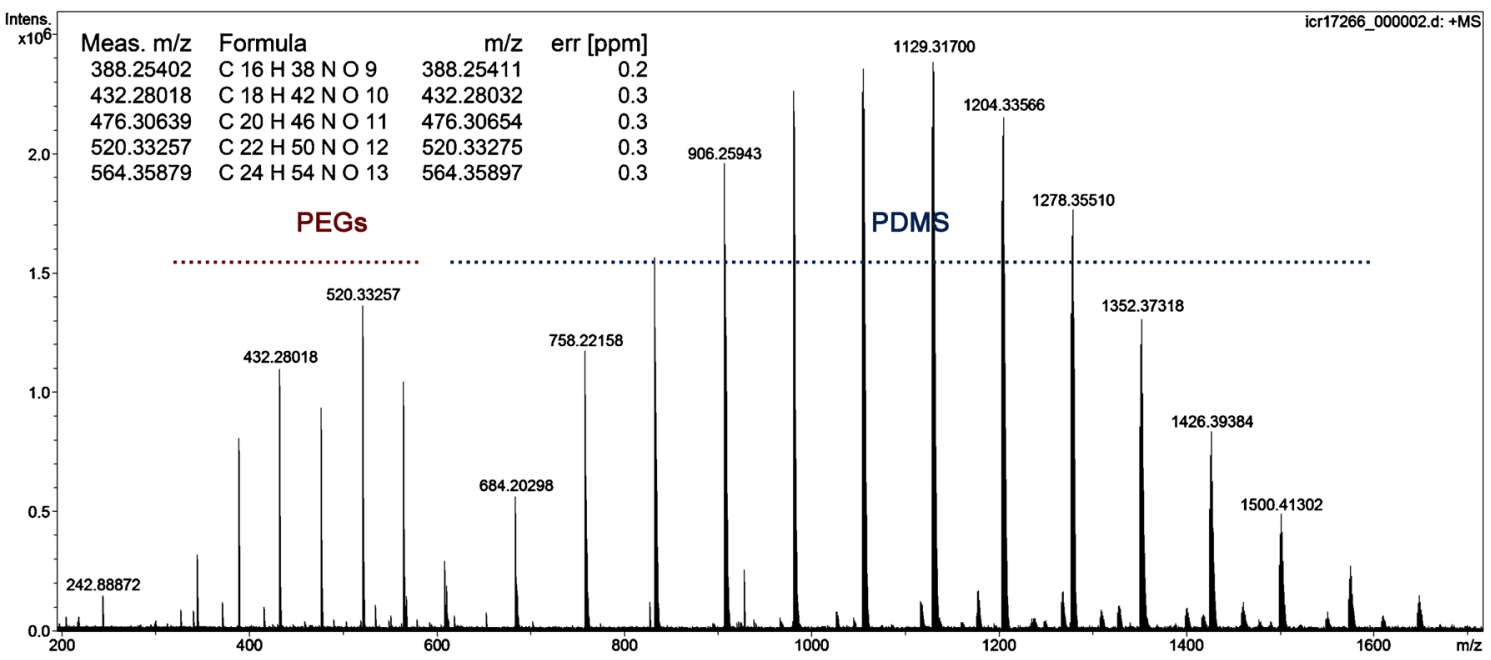

Figure 3. DART-FT-ICR spectrum of a NUK Happy Days pacifier reveals the release of some low-mass polyethylene glycols (PEGs) that are detected as $\left[\mathrm{PEG}+\mathrm{NH}_{4}\right]^{+}$ions in the molecular weight range of 300-600 u. Formulas as obtained from accurate mass are included in the Figure. Silicones are observed starting from $\mathrm{m} / \mathrm{z} 610$

silicone oil for creation of a calibration curve corresponding to $1,4,6,20$, and $100 \mu \mathrm{g}$ of silicone oil applied to the glass slide are shown in Figure S19 of the Supplementary Material. Silicone peaks having relative intensities above $2 \%$ and of $s / n$ $>3$ were retrieved from the spectrum list, exported to Microsoft Excel software, and their individual intensities (in counts) were summed up to yield a total signal count. The increase of the total signal count was not linearly correlated to the amount of sample; instead it was best represented by a logarithmic fit (Figure 4).
This non-linear behavior may be interpreted in terms of saturation as the upper end of the curve corresponded to the DART analysis of a visible silicone oil spot of 3-4 $\mathrm{mm}$ in diameter. The signal obtained thereof represented the maximum of what could be released from such a surface. The objects analyzed had a larger spatial expansion than such a spot and, thus, sample ions may have been generated and collected from an even larger surface, which in turn caused a higher amount of sample ions per run than could be obtained from a silicone oil spot. The sample spot size effect was also

\section{Signal [counts]}

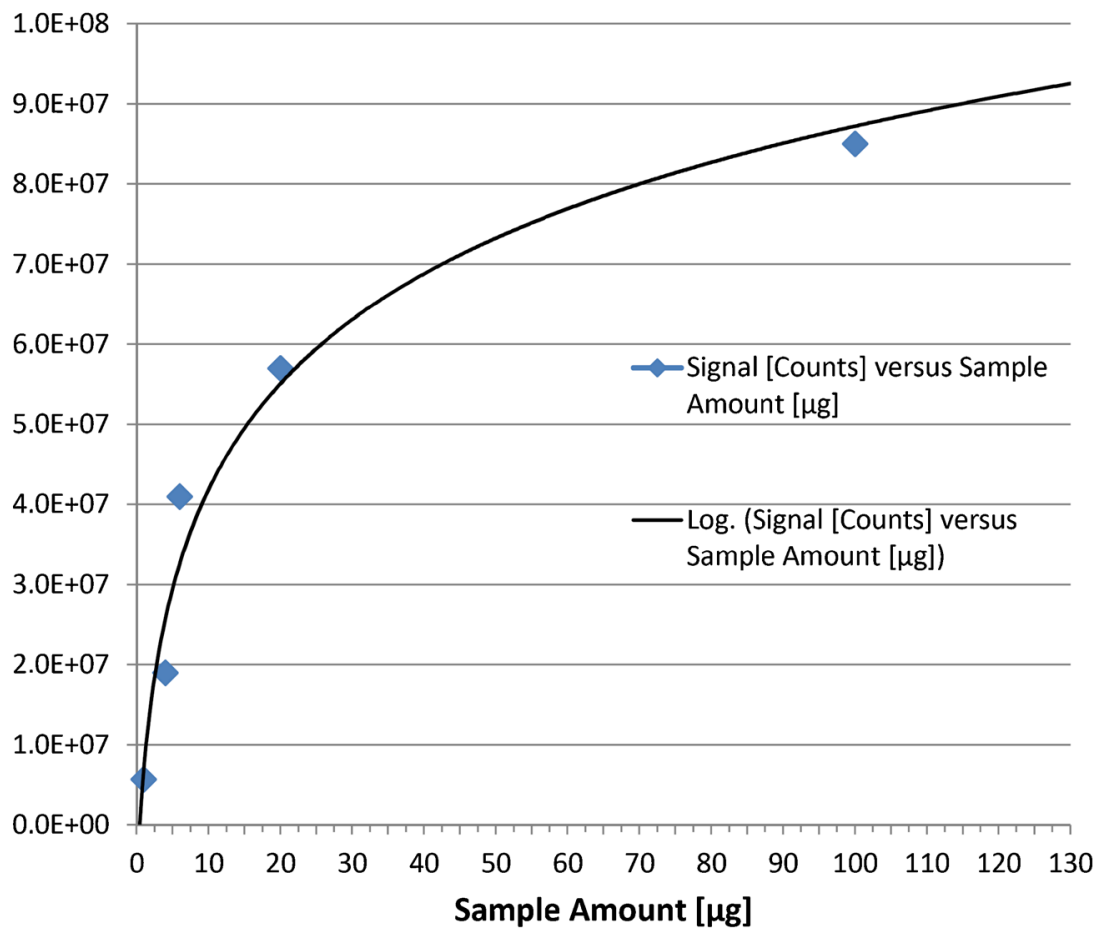

Figure 4. Calibration curve for PDMS based on DART spectra of silicone grease presented on glass slides 
Table 2. Quantification of PDMS Release

\begin{tabular}{llll}
\hline Product & Brand and type & Signal [counts $]^{\mathrm{a}}$ & Amount of PDMS $[\mu \mathrm{g}]^{\mathrm{b}}$ \\
\hline Dough scraper & Farberware Professional & $1.9 \pm 0.7 \times 10^{8}$ & $>100$ \\
Baking mold & Kaiser, rectangular & $8.0 \pm 3.0 \times 10^{7}$ & 70 \\
Baking mold & Pavoni, muffin & $2.0 \pm 0.2 \times 10^{8}$ & $>100$ \\
Baking mold & Pavoni, braided ring & $1.5 \pm 0.3 \times 10^{8}$ & $>100$ \\
Wrist watch & No-name product & $2.3 \pm 0.7 \times 10^{8}$ & $>100$ \\
Pacifier & NUK Happy Days & $8.2 \pm 0.2 \times 10^{7}$ & 80 \\
Pacifier & NUK Happy Kids, latex & $6.5 \pm 2.0 \times 10^{6}$ & 1 \\
Pacifier & Playtex ortho PRO & $1.5 \pm 0.1 \times 10^{8}$ & $>100$ \\
Nipple & Babylove Trinksauger & $6.7 \pm 0.1 \times 10^{7}$ & 35 \\
Nipple & Parents Choice & $1.8 \pm 0.1 \times 10^{8}$ & $>100$ \\
Teething ring & NUK & $1.4 \pm 0.2 \times 10^{8}$ & $>100$ \\
Septum & SGE, silicone, yellow & $5.6 \pm 3.0 \times 10^{7}$ & 20 \\
Septum & Neolab, silicone, blue/white & $1.4 \pm 0.2 \times 10^{8}$ & $>100$ \\
Extraction & Kaiser, rectangular & $1.8 \pm 0.4 \times 10^{7}$ & 2.5 \\
Baking mold & Pavoni, muffin & $1.5 \pm 0.3 \times 10^{7}$ & 2.0 \\
Baking mold & & & \\
\hline
\end{tabular}

${ }^{a}$ Average of 3 to 6 repeat runs (all values are listed in Supplementary Table S1)

${ }^{\mathrm{b}}$ As read from calibration curve (Figure 4) obtained by logarithmic fit through data

observed during the analysis of the SGE yellow silicone septum that was only $5 \mathrm{~mm}$ in diameter and was, thus, found to release only $20 \mu \mathrm{g}$ of PDMS per run (Table 2). With such a tiny object, slight variations in position and angle caused more pronounced variation of the signal than they did during the analysis of somewhat larger items.

Some of the objects delivered total signal intensities well within the range of the calibration curve, whereas most were even beyond the upper level. The amount of silicone released ranged from $1 \mu \mathrm{g}$ to more than $100 \mu \mathrm{g}$. The lowest value was measured for the NUK Happy Kids latex pacifier, which is astonishing in that the latex product was expected to release no silicone at all. Nonetheless, the signals must be attributed to this pacifier as they were clearly visible in the $m / z \quad 1100-1900$ range, reproducible, and definitely different from the silicone background signals in the $m / z$ 536-758 range.
The majority of the silicone rubber products, irrespective of the category of use, were found to release several tens to more than hundred micrograms per analysis (Table 2 and for a detailed compilation of data cf. Supplementary Table S1). Of course, the present quantification is limited in that the system to build the calibration curve cannot exactly mimic the properties of the silicone rubber surfaces. Some values also show noteworthy standard deviations of one-third or even one-half of the average value, whereas others exhibit variations of just a few percent.

Overall, these experiments deliver a solid estimate of the amount of silicone released and reveal that any silicone rubber item does so to a substantial degree. From a consumer's point of view, it is particularly frustrating that the baking molds and the scraper that are all designated to elongated use at high temperature belong in the group of most efficient PDMS releasers.

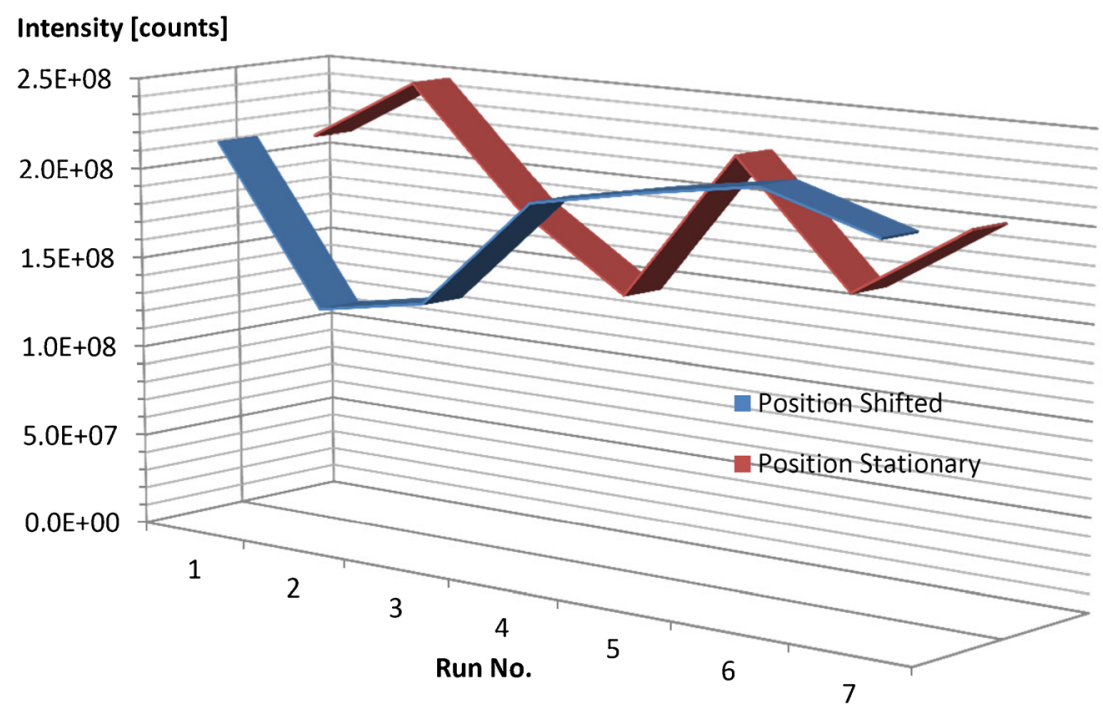

Figure 5. Two series of DART measurements on the dough scraper. Summed PDMS signal intensity data in the front row is obtained by using a fresh spot along the rim with the spots set $1 \mathrm{~cm}$ apart. Data of the back row results from a single spot that was subjected to seven repeat runs (16 s each) with intervals of about $15 \mathrm{~s}$ between runs 


\section{Reproducibility}

Decomposition of the sample material might occur when a spot is exposed to the hot DART gas repeatedly or over an elongated period. Then, a continually increasing fraction low molecular weight oligomers would be formed and be more efficiently ionized, thereby causing an overestimation of PDMS release. Therefore, a control experiment was run on the dough scraper that compared two series of measurements. First, each of seven runs was taken from a fresh spot along one rim of the dough scraper with the spots set $1 \mathrm{~cm}$ apart. Second, the same spot was subjected to seven repeat runs corresponding to $112 \mathrm{~s}$ of total exposure with intervals of about $15 \mathrm{~s}$ between runs, which corresponded to the time required to start the subsequent run on the instrument. Quantification of the PDMS release from those runs yielded an average of $1.9 \pm 0.4 \times 10^{8}$ counts for the series with shifting positions and $2.0 \pm 0.4 \times 10^{8}$ counts for stationary repeat runs on the same spot. As the average value alone might obscure a trend in any of the series, the individual values were depicted in a graph (Figure 5). Obviously, there is no tendency towards an increase of PDMS release due to sample decomposition when a spot is investigated repeatedly.

Another concern is related to the exact position and orientation of the items subjected to DART analysis, which could be critical for the resulting spectra, in particular as the objects generally have curved surfaces. The reproducibility has, therefore, been tested by repeatedly measuring the same item. For each run, the item has been manually held in the ionization zone of the DART interface and fully removed to be repositioned for the next run. The variations were comparatively small, showing no noteworthy effect on the resulting spectra, either in ion distribution or in abundance (Figures S5-S17 of the Supplementary Material). It turned out that minor variations in angle and distances to ionization source and entrance capillary are well tolerated. A measure for shot to shot variation may be deduced from the variation of the quantitation results in last section of the discussion.

\section{Extraction Experiments}

Some difference is to be expected between the DART analysis of a silicone rubber object and its ability to release PDMS under the conditions of its normal use. To provide some insight, small slices of baking molds of two manufacturers were placed in rapeseed oil for $1 \mathrm{~h}$ at $180^{\circ} \mathrm{C}$ to simulate the baking process where the mold is in contact with fatty dough. The oil was then placed on a glass slide and analyzed by DART-MS. A neat rapeseed oil sample was treated the same way. Signals attributable to the rapeseed oil mainly occurred in the range $\mathrm{m} / \mathrm{z} 600$ 700 and were identified as ammonium adducts of diacylglycerides. In contrast, after exposure to silicone rubber baking molds, the oil was found to contain notable amounts of PDMS and the corresponding signals exhibited intensities several times higher than those of the oil (Figure 6). Neglected matrix effects of the rapeseed oil the quantification procedure were also applied to these spectra to provide an estimate of the amount. The signal intensities from PDMS corresponded to $2 \mu \mathrm{g}$

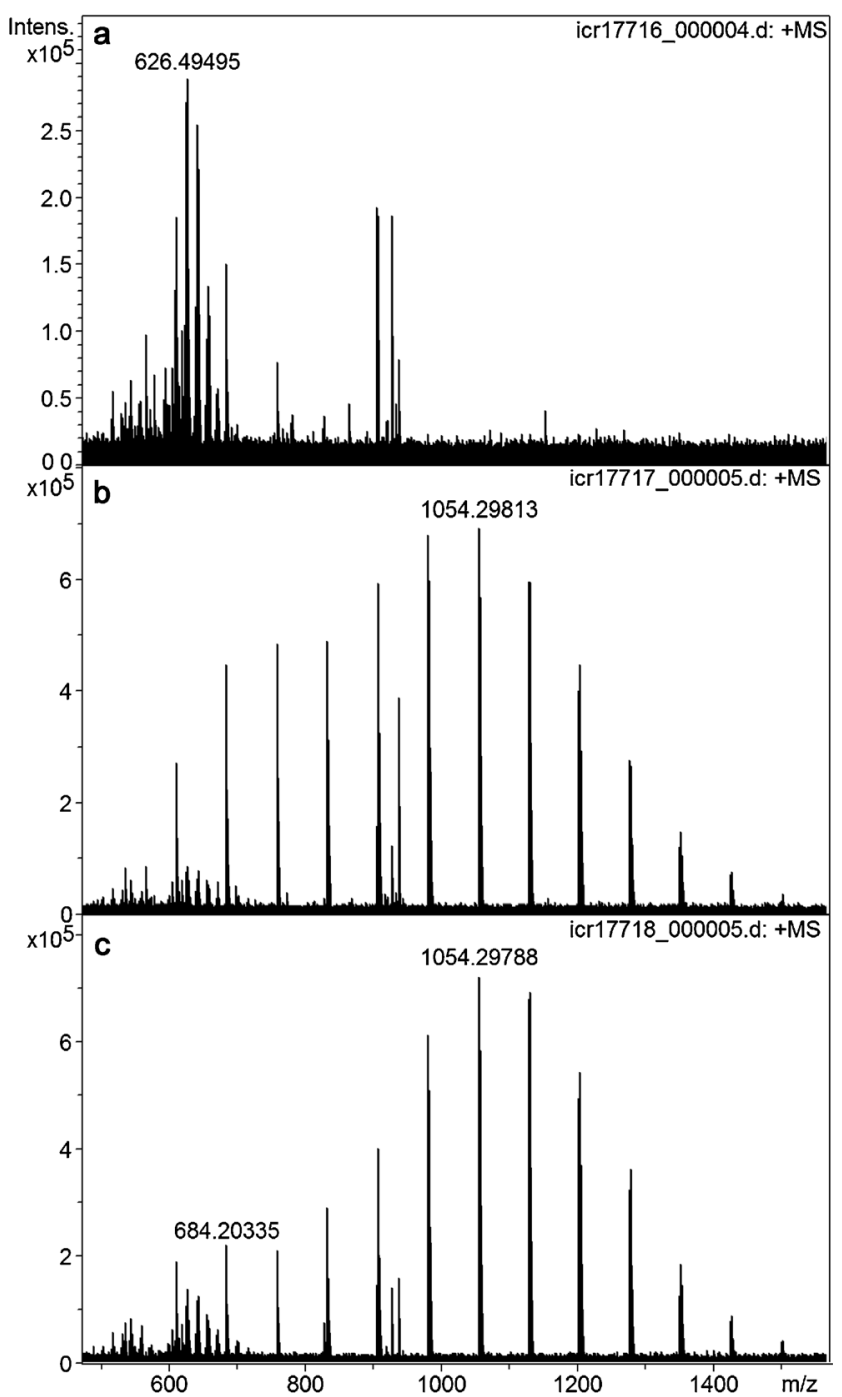

Figure 6. Positive-ion DART spectra of rapeseed oil after simulated baking procedure. (a) Pure rapeseed oil, (b) rapeseed oil in contact with Kaiser mold, (c) rapeseed oil in contact with Pavoni mold. In (b) and (c), the signals due to extracted PDMS are 5- to 10-fold more intense than those of the rapeseed oil, which mainly appears at $m / z 600-700$

of PDMS in $2 \mu \mathrm{L}$ of oil in case of the Pavoni mold and $2.5 \mu \mathrm{g}$ in case of the Kaiser mold. In terms of concentration, this indicates roughly $1 \mu \mathrm{g} \mathrm{mg}^{-1}$ PDMS in the fat content of a cake.

The aqueous extraction of a pacifier and a nipple $(1.0 \mathrm{~g}$ in $10 \mathrm{~mL}$ water at $35^{\circ} \mathrm{C}$ for $15 \mathrm{~h}$ ) did not result in detection of PDMS from the water. At least the release of PDMS into water is very restricted; for milk, however, the situation may change.

\section{Conclusions}

DART-MS is sensitive for the analysis of silicones and can be used to analyze PDMS release from articles of daily use. Differences between the silicone rubber articles were mainly observed in terms of molecular weight distribution and occasional release of other compounds in addition to PDMS. Other 
than that, it turned out that almost any object made of soft silicone rubber does release significant amount of PDMS during DART analysis. The signal intensities observed are directly comparable to those obtained by application of a solution of silicone oil for DART mass calibration. To provide a coarse quantification, a calibration based on silicone oil has been established, which, upon application to the samples, delivers losses from $20 \mu \mathrm{g}$ to $>100 \mu \mathrm{g}$ during the 16 -s period per measurement. Also, extraction of baking molds in vegetable oil showed a clear tendency of silicone rubber to release PDMS at the level of $1 \mu \mathrm{g} \mathrm{mg}^{-1}$ into fat-containing food. These findings indicate a potential health hazard from frequent or long-term use of such items in general.

The selection of samples has been rather arbitrary with the intention to cover some major groups of use. It is not the purpose of this work to blame certain brands of articles made of silicone rubber. Rather, it is intended to create an awareness of this source of daily silicone intake and to initiate improvements of such products wherever possible. The author is well aware of the limited accuracy of quantification, which is sometimes low but often reasonable depending on the article actually analyzed.

Further work is certainly required to substantiate the amounts of silicone release upon actual use of such articles. This kind of analyses should lie in the hands of laboratories specializing in testing of materials or food. Also, in the future, more detailed analytical work should be done to better quantify the release of silicones and to possibly detect them in long-term users of silicone rubber articles.

\section{References}

1. Reyal, F., Feron, J.G., Leman Detour, S., Pourcelot, A.G., Valentin, M., Phillippe, A.C., Levy-Zauberman, Y., Agman, A., Monier, S., Blondel, A., Cothier-Savey, I., Guihard, T., Le Masurier, P., Fitoussi, A., Couturaud, B.: The impact of poly implant prothese fraud on breast cancer patients: a report by the Institut Curie. Plast. Reconstr. Surg 131, 690-695 (2013)

2. Joseph, J., Mohanty, M.: Influence of curing agent on fibrosis around silicone implants. J. Biomater. Sci. Polym. Ed. 24, 1140-1151 (2013)

3. Hajdu, S.D., Agmon-Levin, N., Shoenfeld, Y.: Silicone and autoimmunity. Eur. J. Clin. Invest. 41, 203-211 (2011)

4. Miro-Mur, F., Hindie, M., Kandhaya-Pillai, R., Tobajas, V., Schwartz Jr., S., Alijotas-Reig, J.: Medical-grade silicone induces release of proinflammatory cytokines in peripheral blood mononuclear cells without activating T cells. J. Biomed. Mater. Res. B 90B, 510-520 (2009)

5. Ryona, I., Reinhardt, J., Sacks, G.L.: Treatment of grape juice or must with silicone reduces 3-alkyl-2-methoxypyrazine concentrations in resulting wines without altering fermentation volatiles. Food Res. Int. 47, 70-79 (2012)

6. Cody, R.B., Laramee, J.A., Durst, H.D.: Versatile new ion source for the analysis of materials in open air under ambient conditions. Anal. Chem. 77, 2297-2302 (2005)

7. Cody, R.B.: Observation of molecular ions and analysis of nonpolar compounds with the direct analysis in real time ion source. Anal. Chem. 81, 1101-1107 (2009)

8. Venter, A., Nefliu, M., Cooks, R.G.: Ambient desorption ionization mass spectrometry. Trends Anal. Chem. 27, 284-290 (2008)

9. Weston, D.J.: Ambient ionization mass spectrometry: current understanding of mechanistic theory; analytical performance and application areas. Analyst 135, 661-668 (2010)

10. Green, F.M., Salter, T.L., Stokes, P., Gilmore, I.S., O'Connor, G.: Ambient mass spectrometry: advances and applications in forensics. Surf. Interface Anal. 42, 347-357 (2010)
11. Hajslova, J., Cajka, T., Vaclavik, L.: Challenging applications offered by direct analysis in real time (DART) in food-quality and safety analysis. Trends Anal. Chem. 30, 204-218 (2011)

12. Andrade, F.J., Shelley, J.T., Wetzel, W.C., Webb, M.R., Gamez, G., Ray, S.J., Hieftje, G.M.: Atmospheric pressure chemical ionization source. 1. Ionization of compounds in the gas phase. Anal. Chem. 80, 2646-2653 (2008)

13. Shelley, J.T., Wiley, J.S., Chan, G.C.Y., Schilling, G.D., Ray, S.J., Hieftje, G.M.: Characterization of direct-current atmospheric-pressure discharges useful for ambient desorption/ionization mass spectrometry. J. Am. Soc. Mass Spectrom. 20, 837-844 (2009)

14. Furuya, H., Kambara, S., Nishidate, K., Fujimaki, S., Hashimoto, Y., Suzuki, S., Iwama, T., Hiraoka, K.: Quantitative aspects of atmosphericpressure Penning ionization. J. Mass Spectrom. Soc. Jpn. 58, 211-213 (2010)

15. Hiraoka, K., Ninomiya, S., Chen, L.C., Iwama, T., Mandal, M.K., Suzuki, H., Ariyada, O., Furuya, H., Takekawa, K.: Development of double cylindrical dielectric barrier discharge ion source. Analyst 136, 1210-1215 (2011)

16. Chernetsova, E.S., Morlock, G.E., Revelsky, I.A.: DART mass spectrometry and its applications in chemical analysis. Russ. Chem. Rev. 80, 235255 (2011)

17. Chernetsova, E.S., Morlock, G.E.: Determination of drugs and drug-like compounds in different samples with direct analysis in real time mass spectrometry. Mass Spectrom. Rev. 30, 875-883 (2011)

18. Fraser, K., Lane, G.A., Otter, D.E., Harrison, S.J., Quek, S.Y., Hemar, Y., Rasmussen, S.: Monitoring tea fermentation/manufacturing by direct analysis in real time (DART) mass spectrometry. Food Chem. 141, 2060-2065 (2013)

19. Sparkman, O.D., Jones, P.R., Curtis, M.: Accurate mass measurements with a reflectron time-of-flight mass spectrometer and the direct analysis in real time (DART) interface for the identification of unknown compounds below masses of 500 DA. In: Li, L. (ed.) Chemical Analysis, pp. 229-245. Wiley, NJ, USA, Hoboken (2009)

20. Gross, J.H.: Direct analysis in real time - a critical review of DART-MS. Anal. Bioanal. Chem. 406, 63-80 (2014)

21. Zhao, Y., Lam, M., Wu, D., Mak, R.: Quantification of small molecules in plasma with direct analysis in real time tandem mass spectrometry, without sample preparation and liquid chromatographic separation. Rapid Commun. Mass Spectrom. 22, 3217-3224 (2008)

22. Yu, S., Crawford, E., Tice, J., Musselman, B., Wu, J.T.: Bioanalysis without sample cleanup or chromatography: the evaluation and initial implementation of direct analysis in real time ionization mass spectrometry for the quantification of drugs in biological matrixes. Anal. Chem. 81, 193202 (2009)

23. Nilles, J.M., Connell, T.R., Durst, H.D.: Quantitation of chemical warfare agents using the direct analysis in real time (DART) technique. Anal. Chem. 81, 6744-6749 (2009)

24. Saang'onyo, D., Selby, G., Smith, D.L.: Validation of a direct analysis in real time mass spectrometry (DART-MS) method for the quantitation of six carbon sugars in a saccharification matrix. Anal. Methods 4, 3460-3465 (2012)

25. Haunschmidt, M., Buchberger, W., Klampfl, C.W., Hertsens, R.: Identification and semi-quantitative analysis of parabens and UV filters in cosmetic products by direct-analysis-in-real-time mass spectrometry and gas chromatography with mass spectrometric detection. Anal. Methods 3, 99-104 (2011)

26. Grange, A.H.: Semiquantitative analysis of contaminants in soils by direct analysis in real time (DART) mass spectrometry. Rapid Commun. Mass Spectrom. 27, 305-318 (2013)

27. Chernetsova, E.S., Morlock, G.E.: Assessing the capabilities of direct analysis in real time mass spectrometry for 5-hydroxymethylfurfural quantitation in honey. Int. J. Mass Spectrom. 314, 22-32 (2012)

28. Hintersteiner, I., Sternbauer, L., Beissmann, S., Buchberger, W.W., Wallner, G.M.: Determination of stabilisers in polymeric materials used as encapsulants in photovoltaic modules. Polym. Test. 33, 172-178 (2014)

29. Paseiro-Cerrato, R., Noonan, G.O., Begley, T.H.: Development of a rapid screening method to determine primary aromatic amines in kitchen utensils using direct analysis in real time mass spectrometry (DART-MS). Food Addit. Contam. A 31, 537-545 (2014)

30. Clarke, B.O., Smith, S.R.: Review of emerging organic contaminants in biosolids and assessment of international research priorities for the agricultural use of biosolids. Environ. Int. 37, 226-247 (2011) 
31. Gross, J.H.: Polydimethylsiloxane-based wide range mass calibration for direct analysis in real time mass spectrometry. Anal. Bioanal. Chem. 405, 8663-8668 (2013)

32. Gross, J.H.: Wide range mass calibration for negative-ion direct analysis in real time-mass spectrometry. Eur. J. Mass Spectrom. 20, 155-161 (2014)

33. Perez, J.J., Harris, G.A., Chipuk, J.E., Brodbelt, J.S., Green, M.D., Hampton, C.Y., Fernandez, F.M.: Transmission-mode direct analysis in real time and desorption electrospray ionization mass spectrometry of insecticide-treated bednets for malaria control. Analyst 135, 712-719 (2010)

34. Krechmer, J., Tice, J., Crawford, E., Musselman, B.: Increasing the rate of sample vaporization in an open air desorption ionization source by using a heated metal screen as a sample holder. Rapid Commun. Mass Spectrom. 25, 2384-2388 (2011)

35. Chernetsova, E.S., Crawford, E.A., Shikov, A.N., Pozharitskaya, O.N., Makarov, V.G., Morlock, G.E.: ID-CUBE direct analysis in real time high-resolution mass spectrometry and its capabilities in the identification of phenolic components from the green leaves of Bergenia crassifolia $\mathrm{L}$. Rapid Commun. Mass Spectrom. 26, 1329-1337 (2012)

36. Gross, J.H.: High-mass cluster ions of ionic liquids in positive-ion and negative-ion DART-MS and their application for wide range mass calibrations. Anal. Bioanal. Chem. 406, 2853-2862 (2014)

37. Dong, X., Gusev, A., Hercules, D.M.: Characterization of polysiloxanes with different functional groups by time-of-flight secondary ion mass spectrometry. J. Am. Soc. Mass Spectrom. 9, 292-298 (1998) 